\title{
LINGUÍSTICA APLICADA, SABER GLOCAL E INTERDISCIPLINARIDADE
}

\author{
Eliana Márcia dos Santos Carvalbo*
}

\begin{abstract}
RESUMO: O caráter interdisciplinar da Linguística Aplicada (CELANI, 2000) é abordado neste trabalho, visto que nos últimos anos a palavra interdisciplinaridade tem se tornado frequente na rotina dos docentes e demais profissionais da educação. Este trabalho aponta algumas características deste termo que ainda não tem uma definição precisa por porte dos estudiosos da área e apresenta também reflexões a respeito do saber glocal (CANAGARAJAH, 2005) e sua importância no desenvolvimento das atividades cotidianas da sala de aula. As variações terminológicas de definição da palavra interdisciplinaridade são apresentadas neste artigo com base nos estudos de Pombo (1993), Japiassu (1976) e Fazenda (2011), entre outros autores.
\end{abstract}

PALAVRAS-CHAVE: Interdisciplinaridade; Formação de professor; Linguística Aplicada

Há alguns anos atrás, os meus colegas da Universidade e eu trabalhávamos individualmente, de forma fragmentada, compartimentando cada disciplina em um espaço separado durante as atividades acadêmicas, da mesma forma como aconteceu a nossa formação docente. As disciplinas do curso em que atuávamos eram distribuídas lado a lado, sendo uma pré-requisito da outra, tornando o aluno, a cada semestre, dependente do conhecimento do semestre anterior, como se o conhecimento pudesse ser sequenciado. Em 2004, após

\footnotetext{
* Doutora em Lingüística Aplicada e Estudos da Linguagem pela Pontifícia Universidade Católica de São Paulo (Puc-SP). Professora Adjunta da Universidade do Estado da Bahia (Uneb).
} 
vários debates e com base na experiência dos colegas professores, o currículo foi reformulado, colocando no centro dos estudos a aprendizagem de língua inglesa e a pesquisa acadêmica. Depois de trabalhar alguns anos nesse novo curso e de observar alguns resultados com os meus alunos, a formação do professor tornou-se o principal tema para os meus escritos.

Durante as etapas de reestruturação do curso de Letras, ficou claro para o grupo de professores envolvidos que, através da interdisciplinaridade, é possível ter um conhecimento adequado de determinada situação (realidade). O entendimento era que essa abordagem tinha o pensamento contrário à especialização e consequente fragmentação do conhecimento, já que, muitas vezes, o especialista consegue resolver um problema, mas encontra ou produz outros que não são possíveis de serem resolvidos isoladamente. Depois de implementado o novo currículo, o grupo de professores desenvolveu, durante vários semestres letivos, atividades bem sucedidas de caráter interdisciplinar. A interdisciplinaridade continuava em prática ou os componentes passaram a compor um puzqle disciplinar, situação em que as disciplinas são trabalhadas lado a lado com pequenos momentos de interligação.

Muitos professores parecem estar acorrentados a ideias pré-formadas, pré-estabelecidas, que julgam facilitar o seu fazer profissional e, por isso tudo, fazem vista grossa às inúmeras possibilidades que o trabalho interdisciplinar pode proporcionar. Faz-se necessário o desenvolvimento do senso crítico e a ampliação da visão de mundo, para que sejamos capazes de nos tornar profissionais críticos e questionadores a respeito do que está institucionalizado como ideologia dominante.

\section{Linguística Aplicada: In(ter)disciplinar}

Celani (2000), pontua que a Linguística Aplicada é articuladora de muitos domínios do saber que estão relacionados à linguagem e, por isso, tem um papel fundamental na formação dos indivíduos. Ela afirma que, essa área de conhecimento é muito importante 
no equacionamento de problemas de ordem educacional, social, política e até econômica, ilustrando o seu caráter interdisciplinar.

Dessa forma, a Linguística Aplicada pode favorecer o desenvolvimento

de uma conscientização linguística tanto em relação à língua enquanto sistema, quanto em relação à língua enquanto meio de comunicação socialmente construído e passou a ser preocupação fundamental para muitos linguistas aplicados, quer em programas de formação de docentes, quer em programas de ensino para todos os níveis de escolaridade. (CELANI, 2000: 20)

Essa multiplicidade de possibilidades no campo da pesquisa é possível devido ao fato de a Linguística Aplicada ser interdisciplinar e compartilhar de conhecimentos de outras ciências (Antropologia, Sociologia, Pedagogia, Psicologia, Linguística, etc.) para compreender, dentre outros aspectos, como a linguagem humana acontece em determinado contexto. Com isso, podem-se explicar diversos aspectos do processo de ensino-aprendizagem de línguas estrangeiras por meio da articulação de vários domínios do saber, o que facilita ao professor formador a compreensão e complementação do seu trabalho docente.

Além disso, o cotidiano da sala de aula está intimamente relacionado ao momento social e político de um povo, e a linguagem é fator decisivo para lidar com as situações apresentadas, não só nas aulas de língua (materna e estrangeira), como também de todas as outras disciplinas. A autora enfatiza ainda que a Linguística Aplicada está preocupada não apenas com o ensino de línguas e as circunstâncias que o envolvem, mas também com

o desenvolvimento do senso linguístico que possibilite ao aluno sentir, interpretar e ver a linguagem não apenas como mais uma disciplina do currículo, mas principalmente como algo que está relacionado ao seu cotidiano enquanto cidadão e ser humano. (CELANI, 2000: 20)

Somando-se a isso, também no campo da Linguística Aplicada, Moita Lopes (2006) afirma que essa área de conhecimento dialoga com teorias que estão atravessando o campo das Ciências Sociais e das Humanidades, assumindo assim um caráter Indisciplinar e transgressivo, porque tem a possibilidade de incorporar várias áreas de conhecimento. A partir 
dessa perspectiva, pode-se compreender o campo da linguagem relacionado à aprendizagem de línguas e, assim, os padrões ditos corretos que estão estabelecidos para explicar e estudar a linguagem em seu contexto começam a ser questionados. Esse autor destaca a Linguística Aplicada como um campo de estudo direcionado a diferentes contextos e dá enfoque à interdisciplinaridade, que deve permear a aprendizagem, apontando também para a necessidade de um programa específico para a formação do professor de inglês.

Moita Lopes (2006) reflete a respeito da Linguística Aplicada e da interdisciplinaridade, pontuando que essa abordagem possibilita que escapemos das visões pré-estabelecidas colocadas como corretas e imutáveis, já que a interdisciplinaridade atravessa fronteiras e outras áreas do conhecimento e permite que seja feita uma tessitura que possibilite a visão do processo de aprendizagem de forma ampla. Ele visualiza a possibilidade de construção de um processo de ensino-aprendizagem com foco na linguagem numa variedade de contextos de seu uso, iluminado e construído interdisciplinarmente em um aporte teórico múltiplo.

Essa perspectiva adotada por Moita Lopes (2006) ajuda-nos a compreender a Linguística Aplicada como Indisciplinar porque ela possibilita a criação de situações de inteligibilidade para determinadas situações de aprendizagem em contextos diversos, sem simplificá-los. O autor acima mencionado demonstra uma estreita relação entre a Linguística Aplicada e a Interdisciplinaridade, quando diz:

[...] foi certamente o viés da interdisciplinaridade que causou mais impacto no desenvolvimento da LA contemporânea. E é esse viés que leva à formulação de uma LA mestiça ou nômade [...] o percurso da interdisciplinaridade, na verdade, fez parte da minha educação como linguista aplicado [...] e esse percurso me tornou cada vez mais interessado no que outras áreas de conhecimento tinham a dizer sobre a linguagem. (MOITA LOPES, 2006: 20).

Ao encontrar respostas para os questionamentos em outras ciências, o linguista aplicado percebe o quão multifacetado é o ser humano e que ele é dotado de saberes que, muitas vezes, a escola desconsidera. 


\section{Saber glocal: teoria e prática em sala de aula}

Grande parte desses saberes têm origem no saber glocal. Na Linguística Aplicada, os estudos de Canagarajah (2005) que tratam do saber glocal e da autonomia do professor, mostram que o conhecimento deve ser tratado nas atividades de ensino, e não isoladamente. Por saber glocal compreende-se a junção dos termos local e global para designar o conhecimento originado da experiência particular (local), relacionada com as teorias oriundas de uma cultura global (CANAGARAJAH, 2005; CELANI, 2000). Refere-se ao conhecimento que o professor tem, advindo de sua experiência e que está relacionado às teorias desenvolvidas pelos estudiosos de forma mais ampla.

Seguindo o pensamento de Canagarajah (2005:7), observa-se que o termo conhecimento local não é novo. Mas, como o próprio autor afirma, ele se tornou mais utilizado nas duas últimas décadas, com movimentos eruditos como o pós-colonialismo e os estudos culturais. Para ele, o conhecimento local refere-se a crenças e orientações que surgiram a partir das práticas sociais de uma comunidade ao longo da sua história. Essas crenças têm seus princípios e validade, embora possam se diferenciar do conhecimento de formas válidas no nível global.

No sentido social, o conhecimento local contrasta com o conhecimento oficial que informa as práticas e procedimentos de várias instituições - legal, fiscal e política. As pessoas geralmente desenvolvem discursos extra-institucionais ou vernaculares em sua vida diária sobre como negociar essas relações em seus próprios termos.

No sentido acadêmico, ele se refere ao conhecimento que diverge do que é estabelecido ou legitimado nas disciplinas orientadas pelo sistema. As crenças que não se ajustam aos paradigmas estabelecidos continuam a circular oficialmente no nível local entre os círculos menores.

No sentido profissional, os praticantes do conhecimento local desenvolvem a consciência de que estão trabalhando e utilizando maneiras que não são reconhecidas ou recomendadas pelas autoridades e especialistas (pela academia). Assim, o conhecimento gerado em nossos contextos diários de trabalho, muitas vezes eficaz no processo ensino- 
aprendizagem de língua, pode não agradar o reconhecimento profissional ou erudito. Apesar disso, na maioria das vezes, dão bons frutos.

Continuando a sua análise, Canagarajah (2005) afirma que, apesar dos muitos esforços para perceber o conhecimento local em termos não pejorativos, em muitos círculos, ele ainda é tratado como sabedoria e crenças recebidas sem serem examinadas e comprovadas, sendo, muitas vezes, consideradas irracionais e atrasadas. Talvez por serem frequentemente romantizadas e apresentarem diferenças sutis com relação ao conhecimento científico.

Mais adiante, Canagarajah (2005, p. 17), questiona: “o que nos leva a essa opinião? A essa desvalorização do conhecimento local?’. Ao responder, ele afirma que talvez exista alguma coisa fundamental no processo de construção de conhecimento que explica esta parcialidade. A criação de generalização, sistematização e modelo envolve uma certa quantia de abstração que filtra a variabilidade de experiência em diversos contextos.

$\mathrm{Na}$ formação de professor de línguas no Brasil, encontramos problemas quando o conhecimento local colide com o conhecimento especializado. Lai (2003) considera que o conhecimento profissional pode ser visto como aquele que o professor, dentro do seu campo profissional, aprende e aprimora na medida em que desenvolve as atividades docentes. O que ele de fato aprende da sua experiência na prática profissional constitui uma parte muito importante nomeada conhecimento pessoal, intimamente relacionado ao conhecimento local, pois é fruto de experiências vividas em um local e cultura específicos. O autor salienta que os professores não devem considerar que seu conhecimento é inferior ao dos teóricos, ao contrário, deve compreender que ele constitui um co-conhecimento e aliá-lo à teoria para desenvolver sua prática, procurando sempre integrar teoria e prática nas atividades da sala de aula. Daí surge o saber glocal.

Considerado um neologismo, o saber glocal, reúne duas palavras conflituosas: globalização e localização. A ideia leva-nos a pensar numa realidade complexa, paradoxal e a visualizar saídas para algumas situações na área da educação, ao mesmo tempo em que nos ajuda a resolver determinadas adversidades. Para Perissé (2012), a glocalização possibilita 
perceber que não existe um caminho único para a resolução de problemas. Se conseguirmos unir os dois termos, podemos evitar a destruição da variedade cultural, a criatividade de cada povo e a beleza específica de cada um. Com a glocalização têm-se a diminuição do complexo de inferioridade e os valores culturais são compartilhados e valorizados. Nesse sentido, o autor reforça que, glocalizar é localizar o global, mas jamais deslocalizar o que temos de original, é localizar o universal dentro de uma realidade específica.

Por outro lado, Freeman (2000) faz uma analogia a respeito do saber glocal, narrando uma história ouvida no rádio. A história diz o seguinte: um acadêmico viveu a sua infância às margens de um Rio, denominado Niger, e provavelmente ainda não catalogado pelas enciclopédias até aquela data. A aldeia à qual pertenciam os familiares desse acadêmico viveu por décadas às margens daquele Rio sem saber a sua nomenclatura e, para eles, isso não tinha importância. Nos anos da sua infância, quando cursava o Ensino Básico, ele aprendeu numa enciclopédia da biblioteca de sua escola, que aquele Rio, palco de seus sonhos e brincadeiras de criança, foi descoberto em 1796 por um escocês, e foi assim nomeado. Essa situação o deixou intrigado e o fez questionar como os seus antepassados poderiam ter vivido as suas margens, tirando dali o seu sustento, sem nunca o nomear? $\mathrm{Na}$ realidade isso não tinha importância...

Quando Freeman (2000) ilustra esta situação, ele quer explorar a noção do Rio estar sempre ali e não ser nomeado formalmente. Assim também são as experiências da sala de aula. Há um "rio" em cada professor, mas muitos acreditam que ele precisa ser "descoberto" pela academia, instância onde supostamente as teorias são criadas. Especificamente, para Freeman (2000: 2, tradução minha), “o conhecimento do professor e o rio que ainda não foi reconhecido porque não foi formalmente mapeado ou nomeado". Cada professor traz em si uma experiência de vida relativa às atividades e circunstâncias da sala de aula que ainda não foram pesquisadas e teorizadas, porém, a maioria não tem consciência de que possui esse conhecimento.

O conhecimento é uma ferramenta que deve ser usada por aquele que a domina, pois como ferramenta, ela vem com uma herança que é moldada por quem a utiliza. Os 
usuários podem criar e modificar a ferramenta (conhecimento) de acordo com a situação. Se isso não acontecer, ela não terá um fim em si mesma. Existe a suposição de que as ideias podem ser importadas e continuarem sendo as mesmas, no entanto, necessária se faz a adaptação para ser utilizada de acordo com o contexto. $\mathrm{O}$ autor anteriormente citado, num sentido mais amplo, afirma que todo conhecimento vem de algum lugar: da experiência profissional ou pessoal. Embora esse conhecimento possa vir de qualquer lugar, ele é sempre usado localmente e, nesse uso, ele é recriado e/ou reformulado. A percepção do conhecimento pelo professor é ilustrada na figura a seguir:

Figura 1 - Reflexões sobre o de conhecimento do professor

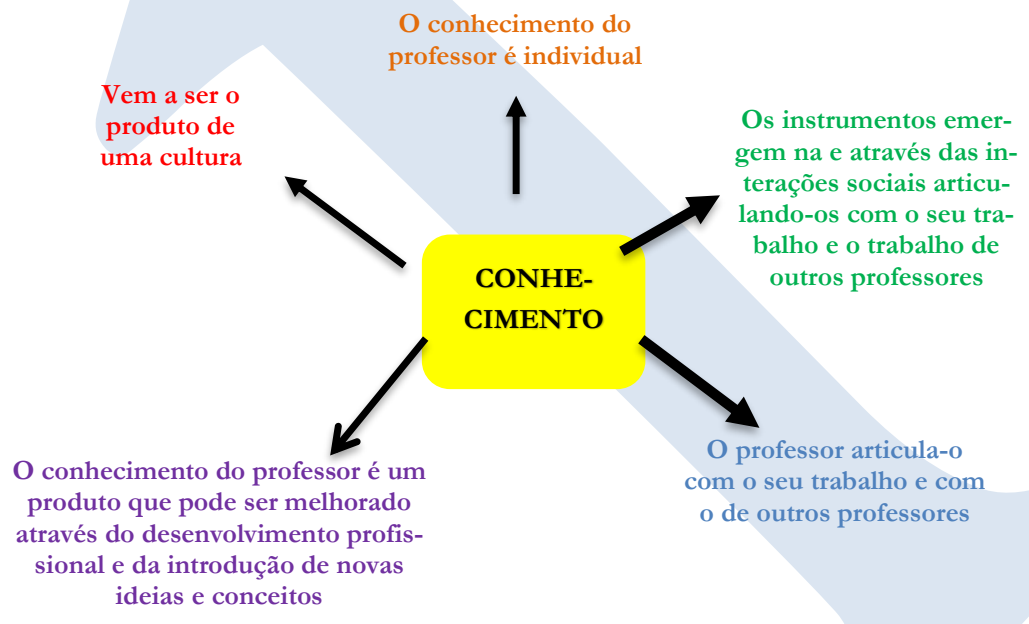

Fonte: Elaboração da autora 


\section{A palavra disciplina e a multiplicidade de conceitos}

Há tempos o termo interdisciplinaridade tem recebido muitas tentativas de uma definição teórica e objetiva, o que não tem logrado êxito por parte dos pesquisadores (JAPIASSU, 1976; FAZENDA, 1979; POMBO, 2004), pois o termo interdisciplinar é muito abrangente e não se "encaixa" numa definição específica, objetiva ou pontual. A interdisciplinaridade tem a ver com a "incapacidade que todos temos para ultrapassar os nossos próprios princípios discursivos, as perspectivas teóricas e os modos de funcionamento em que fomos treinados, formados, educados” (POMBO, 2004: 37).

Na década de 1960, os alunos de Jean Piaget perceberam a forte fragmentação que ocorria com o conhecimento, levando o ser humano a afunilar, cada vez mais, o conhecimento, tendo como consequência a especialização. Daí surgiu um forte movimento pela integração disciplinar que, ainda hoje, é tema de conversas, seminários e ações acadêmicas. A hiperespecialização passou a ser questionada e criticada. Gusdorf (apud JAPIASSU, 1976) considera o especialista aquele que possui um conhecimento cada vez mais extenso relativo a um domínio cada vez mais restrito, considerando o triunfo da especialização o saber tudo sobre nada. Ele acredita que, quanto mais diversificado fica o conhecimento, mais distante ele fica da realidade humana. Esse mesmo autor ainda afirma que a "ciência em migalhas de nossa época não passa de reflexo de uma consciência esmigalhada, incapaz de formar uma imagem de conjunto do mundo atual" (JAPIASSU, 1976: 20). Na sequência do pensamento, ele faz um apelo para que busquemos uma nova epistemologia, que não reflita apenas cada ciência de modo particular, separada do resto, mas sim busquemos em comum a restauração das significações humanas do conhecimento. Para isso, é necessário que o homem da especialidade queira ser, ao mesmo tempo, o homem da totalidade. Gusdorf, nesse mesmo texto considera estar o saber adoecido, tendo como causa o desequilíbrio ontológico e a ciência dividida em migalhas, ao que Japiassu (1976: 23) nomeia "patologia contemporânea do saber [...] O remédio à desintegração do saber consiste em trazer, à dinâmica da especialização, uma dinâmica compensadora de não especialização”. O estudioso considera ser a interdisciplinaridade esse remédio. 
Percebe-se a necessidade de ampliação do olhar do homem sobre o homem. O conhecimento especializado reduz o homem a pequenos compartimentos, sendo necessária uma nova epistemologia que congregue especialidades diversas, visualizando o homem e o conhecimento como um todo. Nesse ponto, o pensamento de Fazenda (2001) tornase claro. Ela fala da humildade necessária para que cada especialista perceba seus limites e saiba ouvir sensivelmente o que o outro tem a compartilhar.

Para tratar do tema interdisciplinaridade, começarei pelo conceito da palavra disciplina e suas variações, pois dela derivaram outros termos que nos confundem no sentido e no significado:

disciplina (lat. Disciplina: ação de aprender, educação) 1. No sentido genérico, toda matéria suscetível de um ensino. Ex.: as disciplinas literárias, científicas. 2. Pedagogicamente, conjunto de regras e normas impostas aos alunos. 3. No sentido vulgar, conjunto das regras de conduta impostas aos membros de uma coletividade. Ex. disciplina militar. 4. Na filosofia de Foucault, "conjunto de regras e técnicas particulares (vigilância hierárquica, sanção normatizadora, exame) tendo por efeito produzir uma conduta normatizada e padronizada, adestrar os indivíduos e submetê-los a uma forma idêntica a fim de otimizar suas faculdades produtivas" (Sébastien Charles). (JAPIASSU, 1934: 76).

Por ter um conceito não tão simples, a palavra disciplina foi considerada por Fazenda (1979: 54), como "um conjunto específico de conhecimentos com suas próprias características sobre o plano do ensino, da formação dos mecanismos, dos métodos, das matérias". Em outro texto, essa autora afirma não haver unanimidade para a definição de cada disciplina acadêmica.

Em Portugal, quando lá estive para estágio doutoral, encontrei, nas ações e no pensamento de Pombo (2004), uma proposta de definição, e ela diz que este radical comum ao 'invés de funcionar como elemento de aproximação, constitui um novo procedimento de dispersão de sentido", ao mesmo tempo ela atribui três significados à palavra disciplina:

Disciplina como ramo do saber: a Matemática, a Física, a Biologia, a Sociologia ou a Psicologia são disciplinas, ramos do saber ou, melhor, alguns desses grandes ramos. Depois, temos as sub-disciplinas 
e assim sucessivamente. Disciplina como componente curricular: História, Ciências da Natureza, Cristalografia, Química Inorgânica, etc. Claro que, em grande medida, muitas das disciplinas curriculares se recortam sobre as científicas, acompanham a sua emergência, o seu desenvolvimento, embora, como sabemos, sempre com defasamentos temporais e inexoráveis efeitos de desvio. Finalmente, disciplina como conjunto de normas ou leis que regulam uma determinada actividade ou o comportamento de um determinado grupo: a disciplina militar, a disciplina automobilística ou a disciplina escolar, etc. (POMBO, 2004: 4).

Em outro texto, Pombo (1993) considera que a palavra disciplina tanto se aplica às disciplinas científicas - ramos do saber - como às disciplinas escolares - entidades curriculares. Ainda sobre a palavra disciplina, Pombo (2004: 163) cita conceitos de outros autores para especificar a sua descrição:

- Conjunto específico de conhecimentos que têm as suas características próprias no terreno do ensino, da formação, dos mecanismos, dos métodos e dos materiais. (BERGER, 1972).

- Uma disciplina trata de uma certa categoria de fenômenos que ela visa tornar inteligíveis e a propósito dos quais procura fazer previsões possíveis ou, mais geralmente, estabelecer correspondências. (PALMADE, 1979).

Com base em Heckhausen (1972), Pombo (2004) ainda esclarece:

O termo disciplina pode ser usado no mesmo sentido que o de "ciência", ainda que inclua a noção de "ensino de uma ciência". Embora haja diferença entre a disciplina como actividade de investigação e a disciplina como actividade de ensino; no entanto, a ciência é ciência porque os resultados da investigação são necessariamente, comunicados publicamente. A comunicação (e o ensino que nela está incluído) é uma parte substancial do processo de clarificação do processo científico e, portanto, da ciência mesma. São sete os critérios que permitem distinguir uma disciplina cientifica de outras: 1) o domínio material ou objecto de estudo; 2) o conjunto possível de fenômenos observáveis; 3) o nível de integração teórica; 4) os métodos; 5) os instrumentos de análise; 6) as aplicações práticas; e 7) as contingências históricas. (POMBO, 2004: 164). 
Novamente no Brasil, o pensador Japiassu (1976) elaborou um conceito sobre disciplina, dada a necessidade de precisar o sentido e estabelecer o seu significado. Para ele, disciplina tem o mesmo sentido de "ciência" e

"disciplinaridade" significa a exploração científica especializada de determinado domínio homogêneo de estudo, isto é, o conjunto sistemático e organizado de conhecimentos que apresentam características próprias nos planos do ensino, da formação, dos métodos e das matérias. Esta exploração consiste em fazer surgir novos conhecimentos que se substituem aos antigos. (JAPIASSU, 1976: 72).

Dessa especialização científica, novos conhecimentos vão surgindo e antigos problemas são solucionados. Há um enriquecimento no campo das ciências através das novas informações que são sistematizadas. Muitas vezes, ocorre o empréstimo de conhecimento de uma ciência para a outra, dando origem às diversas terminologias que são associadas à palavra disciplina.

Quando busquei na internet um conceito para a palavra disciplina, fiquei surpresa ao constatar que ela é vista principalmente sob o foco de regra moral, de conduta social e/ou código de conduta. Continuando a busca, especifiquei o termo na rede e digitei "disciplina científica" e, nessa ocasião, ela foi tratada como uma área de estudo ou ramo do conbecimento. É fato que essa palavra tem significação múltipla e que pode ser utilizada em diversas situações. No entanto, o ponto central desta pesquisa é a interdisciplinaridade, e a palavra disciplina, que é o núcleo deste termo, tem a ver com epistemé- conhecimento.

O status de disciplina só pode ser atribuído ao conjunto de conhecimentos que tem um tema específico originado de um problema e que responde, possivelmente, a perguntas de natureza intelectual, existencial e científica. Assim, a base da palavra interdisciplinaridade - disciplina - pode ser vista como um pilar a que se agregam prefixos e sufixos, que dão origem a termos bem mais amplos. 


\section{Interdisciplinaridade: uma tentativa de definição}

A palavra interdisciplinaridade é dotada de equivocidade ${ }^{1}$, o que dificulta a sua definição. O filósofo Japiassu (1976) chegou a fazer uma diferenciação entre pluri/ multi / inter e transdisciplinaridade. Para ele, a terminologia não é tão simples, pois ainda não dispomos de conceitos necessários para exprimir o pensamento. Segundo esse autor, é necessário esclarecer o significado do termo disciplinaridade, para, a partir daí especificar os demais.

Para Japiassu (1976), os termos multi- e pluridisciplinaridade chegam a ser confundidos pelos professores. O primeiro evoca uma simples justaposição em um trabalho determinado dos recursos de várias disciplinas, sem implicar, necessariamente, um trabalho de equipe coordenado; ao passo que o segundo, a pluridisciplinaridade, faz realizar um trabalho no qual as atividades são desenvolvidas como se as disciplinas estivessem distribuídas uma ao lado da outra, tendo uma centralizada, considerada mais importante, que coordena as atividades das demais. No ensino brasileiro, geralmente, essas disciplinas centrais são a Língua Portuguesa e a Matemática.

A pluridisciplinaridade é considerada como mera justaposição de disciplinas que têm algo em comum em determinada área, sendo possível acontecer intercomunicação em determinado momento do desenvolvimento das atividades escolares, como por exemplo: Química e Física; já o termo transdisciplinaridade possui um significado tão profundo que muitos autores não acreditam ser possível que ela aconteça no atual processo educacional,

A interdisciplinaridade ultrapassa a pluridisciplinaridade porque vai mais longe na análise e confrontação das conclusões, porque procura a elaboração de uma síntese a nível de métodos, leis e aplicações, porque preconiza um regresso ao fundamento da disciplina, porque revela de que modo a identidade do objecto de estudo se complexifica através dos diferentes métodos das várias disciplinas e explicita a sua problematicidade e mútua relatividade. (RESWEBER, apud Pombo, 2011: 11).

${ }^{1}$ Termo utilizado para designar o pluralismo de interpretações; ambiguidade. 
Apresento uma sinopse conceitual a respeito da disciplinaridade e seus afixos. Ante a urgente necessidade de especialização que os profissionais da educação aparentam ter e que o sistema educacional exige, o viés filosófico de Japiassu (1976) aborda essa emergência, que proporciona a especialidade ao mesmo tempo em que isola e fragmenta o conhecimento. Ele estabelece diferenças entre as facetas que a disciplinaridade pode apresentar:

Multidisciplinaridade: gama de disciplinas que propomos simultaneamente, mas sem fazer aparecer as relações que podem existir entre elas.

Pluridisciplinaridade: justaposição de diversas disciplinas situadas geralmente no mesmo nível hierárquico e agrupadas de modo a fazer aparecer as relações existentes entre elas.

Interdisciplinaridade: axiomática comum a um grupo de disciplinas conexas e definidas no nível hierárquico imediatamente superior, o que introduz a noção de finalidade.

Transdisciplinaridade: coordenação de todas as disciplinas e interdisciplinas do sistema de ensino inovado, sobre a base de uma axiomática geral. (JAPIASSU, 1976: 74).

A diversidade de conceitos nos faz compreender que a interdisciplinaridade não é justaposição de disciplinas diversas, às vezes sem relação aparente entre elas. É preciso haver conexão entre conteúdos. Além de um ponto comum entre os conteúdos, estudos desenvolvidos no Brasil mostram que é preciso levar em consideração a postura do professor ante os fatos que surgem em sala de aula.

\section{A interdisciplinaridade no Brasil}

No Brasil, a interdisciplinaridade teve seus estudos marcados na década de 60 e fortalecidos até os dias atuais, através dos estudos da pesquisadora Ivani Fazenda. Imbuída de base teórica advinda dos campos da Sociologia, Psicologia, Antropologia e Educação, essa autora estabeleceu os princípios da interdisciplinaridade como uma "questão de atitude diante do problema do conhecimento" (FAZENDA, 1979: 71)

Para Fazenda (2011: 59), a interdisciplinaridade é uma atitude diante da situação apresentada, "é uma atitude de abertura, não preconceituosa, em que todo o conhecimento 
é igualmente importante. Pressupõe o anonimato, pois o conhecimento pessoal anula-se diante do saber universal". Ela é vivida! Para essa pesquisadora, é preciso saber ser (como explicarei adiante). Ela ainda afirma que há variação no nome, no conteúdo e na forma de atuação num trabalho interdisciplinar. Depois de analisar as definições de um grupo de estudiosos desse tema, dentre eles Piaget, Japiassu, Hechausen e Jantsch, ela traz à baila as seguintes definições terminológicas:

Disciplina - diferentes domínios do conhecimento, na medida em que são sistematizados de acordo com determinados critérios.

Multidisciplina - justaposição de disciplinas diversas, desprovidas de relação aparente entre elas. Ex.: música + matemática + história.

Pluridisciplina - justaposição de disciplinas mais ou menos vizinhas nos domínios de conhecimento. Ex.: domínio científico: matemática + física.

Multi e pluridisciplinaridade - atitude de justaposição de conteúdos de disciplinas heterogêneas ou a integração de conteúdos numa mesma disciplina, atingindo, quando muito, o nível de integração dos métodos, teorias ou conhecimentos.

Interdisciplina - interação existente entre duas ou mais disciplinas. Essa interação pode ir da simples comunicação de ideias à integração mutua dos conceitos diretores da epistemologia, da terminologia, da metodologia, dos procedimentos, dos dados e da organização referentes ao ensino e à pesquisa. Um grupo interdisciplinar compõe-se de pessoas que receberam sua formação em diferentes domínios do conhecimento (disciplinas) com seus métodos, conceitos, dados e termos próprios.

Interdisciplinaridade - relação de reciprocidade, de mutualidade, ou melhor, um regime de corporeidade que iria possibilitar o diálogo entre os interessados. Neste sentido, pode dizer-se que a interdisciplinaridade depende basicamente de uma atitude. Nela a colaboração entre as diversas disciplinas conduz a uma "interação", a uma intersubjetividade como única possibilidade de efetivação de um trabalho interdisciplinar. (grifos da autora)

Transdisciplinaridade - nível mais alto das relações iniciadas nos níveis multi, pluri e inter. (FAZENDA, 2011: 58-68).

O trabalho de Ivani Fazenda diferencia-se dos demais autores pelo fato de ela apresentar uma proposta de trabalho humanitária, na qual o aluno é visto de forma integral. Seus aspectos afetivos e sua história de vida também são levados em conta no processo de 
ensino-aprendizagem, além dos aspectos teóricos e metodológicos. Ela afirma que o trabalho interdisciplinar não pode ser uma mera junção de disciplinas, e define interdisciplinaridade como uma atitude de ousadia e busca frente ao conbecimento, na qual é possível pensar aspectos relacionados à cultura do lugar onde se formam professores. Nesse aspecto, o pensamento de Fazenda (2008) é semelhante ao de Canagarajah (2005), quando trata da importância do saber glocal.

\title{
Considerações conclusivas
}

O grande desafio lançado ao pensamento e à educação, nos dias de hoje, é a contradição entre um saber cada vez mais globalizado, interdependente. Por outro lado, na realidade continuamos alimentando o conhecimento, privilegiando os saberes especializados e fragmentados. Existe a necessidade e a urgência de desenvolver e também promover uma visão interdisciplinar como uma abordagem social, educacional e cultural entre as disciplinas. Não é conveniente continuarmos lidando com o conhecimento sem considerar a totalidade em que cada situação acontece e suas circunstâncias. A alteridade e as contribuições de vários conhecimentos sintetizam que é necessário transgredir disciplinas e conceitos, a fim de construir o conhecimento "interdisciplinar", pois com o trabalho colaborativo os temas, por mais diversificados que sejam, serão melhor abordados.

\section{APPLIED LINGUISTICS, GLOCAL KNOWLEDGE, AND INTERDISCIPLINARITY}

\begin{abstract}
The interdisciplinary nature of Applied Linguistics (CELANI, 2000) is addressed in this paper, since in recent years the word interdisciplinarity has become common in the routine of teachers and other professionals of education. This work points out some characteristics of this term that still do not have an objective definition by the researchers and presents some reflections about the glocal knowledge (CANAGARAJAH, 2005), its importance in the development of the daily activities of the classroom. The terminological variations of the word interdisciplinarity are presented in this article based on studies by Pombo (1993), Japiassu (1976) and Fazenda (2011) among other authors.
\end{abstract}

KEY WORDS: Interdisciplinarity; Teacher training; Applied Linguistic 


\section{REFERÊNCIAS}

CANAGARAJAH, A.S. Reconstructing local knowledge, reconfiguring language studies: Reclaiming the local language policy and practice. Mahwah: Erlbaum. 2005

CELANI, M. A. A. A relevância da linguística aplicada na formulação de uma política educacional brasileira. In: FORTKAMP, M. B. M. Aspectos da Linguística Aplicada. Florianópolis: Insular. 2000

FAZENDA, I. C. A. O que é interdisciplinaridade. São Paulo-SP: Cortez Editora. 2008 Integração e Interdisciplinaridade no ensino Brasileiro, 6. Ed. São Paulo-SP: Edições Loyola.1979

. Dicionário em construção: interdisciplinaridade. São Paulo-SP: Cortez. 2001

. Integração e interdisciplinaridade no ensino brasileiro: efetividade ou ideologia. 6. ed. São Paulo-SP: Loyola. 2011

FREEMAN, D. Imported theories/local understandings: Part 1. Tesol Matters, vol. 10, n 4, October/November. 2011

JAPIASSU, H; Marcondes, D. Dicionário Básico de Filosofia. 5. ed. Rio de Janeiro: Jorge Zahar. 1934

JAPIASSU, H. Interdisciplinaridade e patologia do saber. Rio de Janeiro: Imago Editora. 1976

LAI, C. Personal knowledge and teacher education. IATEFL. UK: Teacher Development Special Interest Group. 2003

MOITA LOPES, L. P. Por uma linguística indisciplinar. São Paulo: Parábola. 2006

PERISSÉ, G. Glocalização. Disponível em <www.escoladeescritores.org>.br Acesso em 30/08/2012.

POMBO, O. A interdisciplinaridade: reflexão e experiência. Lisboa-PT: Texto Editora. 1993 . Interdisciplinaridade: ambições e limites. Viseu-PT: Relógio D’Água Editores. 2004

Recebido em: 28/05/2019. Aprovado em: 30/07/2019. 